\title{
MECHANICAL BEHAVIOUR OF ANTARCTIC ICE
}

\author{
by
}

\author{
P. Duval and H. Le Gac \\ (Laboratoire de Glaciologie et Géophysique de l'Environnement, 2 rue Très-Cloîtres, \\ 38031 Grenoble Cedex, France)
}

ABSTRACT

The mechanisms of Antarctic ice deformation are discussed. Diffusional flow (Nabarro-Herring or Coble creep) seems to dominate creep for the first $905 \mathrm{~m}$ near Dome C. Formation mechanisms of single-maximum fabrics are examined. Dislocation creep does not explain the preferred c-axis orientation observed in the Antarctic ice sheet. The quantitative effects of crystallographic orientation on strain-rate are given. The activation energy for dislocation creep was found to be $78 \mathrm{~kJ}$ mol ${ }^{-1}$ between $-7.2^{\circ} \mathrm{C}$ and $-30^{\circ} \mathrm{C}$. Ratelimiting mechanisms are discussed.

\section{INTRODUCTION}

In order to develop theoretical models for the flow of ice masses, it is necessary to know the constitutive law for the non-elastic deformation of polycrystalline ice. For steady state and multiaxial stresses, it is generally assumed that strain-rates $\dot{\varepsilon}_{i j}$ are related to the corresponding deviatoric stresses by

$$
\dot{\varepsilon}_{i j}=\frac{\tau^{\prime}}{2 \eta} i j=\frac{B}{2} \tau^{n-1} \tau^{\prime} i j,
$$

where $n$ is viscosity, $B$ and $n$ are constants, and $\tau$ is the effective shear stress defined by $\tau^{2}=1 / 2 \Sigma_{i j}\left(\tau^{i} j j^{2}\right)^{2}$.

Equation (1) was verified by Duval (1976) with creep tests on isotropic polycrystalline ice in torsion, compression, and torsion-compression. The exponent $n$ is about 3 , at least over the stress range $0.1 \mathrm{MPa}<\tau<0.5 \mathrm{MPa}$. For low stresses and smal1 grain sizes, diffusional creep is the dominant creep mechanism with $n=1$ (Goodman and others 1981).

Equation (1) cannot be used when fabrics (preferred orientation of the c-axis) have been created. Natural ice masses exhibit strong crystallographic anisotropy, as observed by Gow and Williamson (1976) in the Byrd ice core.

The aim of this paper is to determine the deformation mechanisms of Antarctic ice and to explain the formation of the typical single-maximum fabrics. The influence of preferred c-axis orientation of the ice crystals on the creep behaviour and the variations of strain-rate with temperature are also discussed.

\section{DEFORMATION MECHANISMS OF ANTARCTIC ICE}

\subsection{Crystalline texture of the Dome $C$ ice core}

Changes in crystal size with increasing depth for the $905 \mathrm{~m}$ long Dome $\mathrm{C}$ ice core were described by Duval and Lorius (1980). Four typical thin-section photographs showing the crystalline texture of ice

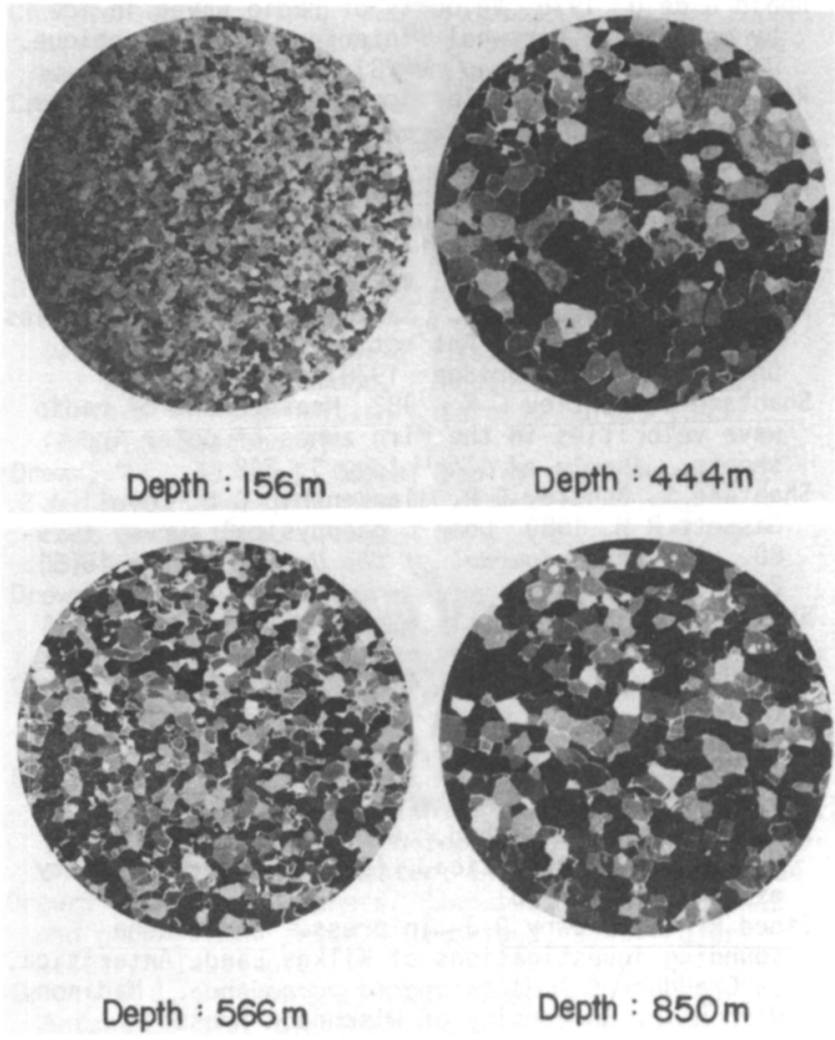

Fig.1. Thin-section photographs of crystalline texture of ice in Dome $C$ ice core between crossed polaroids (XI).

are presented in Figure 1. The expected increase of crystal size with age is observed down to $400 \mathrm{~m}$. At greater depths, a significant decrease of crystal size is associated with the transition from the last glacial age to present climatic conditions. However, as shown in Figure 1, the typically equant texture of crystals is observed down to $905 \mathrm{~m}$. The driving force for grain growth is thus probably only provided by the surface free energy of grain boundaries. The larger crystals grow at the expense of the smaller ones. A distribution of grain sizes is necessary for grain growth. From Duval and Lorius (1980), the total microparticle content in the glacial ice in the Dome $C$ ice core seems too low for them to inhibit grain growth. 
1.2 Deformation mechanisms in the first $905 \mathrm{~m}$ near Dome C

For the first $900 \mathrm{~m}$ of the ice sheet near Dome $C$, shear stress caused by the surface slope is too small to produce significant shear strain. However, the ice mass is plasticaliy thinned with depth and the vertical velocity, for a constant thickness of ice $H$, is given by

$$
w=-\frac{b}{H}\left(z-z_{m}\right),
$$

where $b$ is the accumulation rate, $z$ the distance from the bottom, and $z_{m}$ a constant (Liboutry in press).

$$
\begin{aligned}
& \text { The strain rate } \dot{\varepsilon}_{\mathbf{Z Z}} \text { is } \\
& \qquad \dot{\varepsilon}_{\mathbf{Z Z}}=\frac{\partial W}{\partial z}=-\frac{b}{H},
\end{aligned}
$$

with $b=4 \times 10^{-2} \mathrm{~m} \mathrm{a}^{-1}$ and $\mathrm{H}=3400 \mathrm{~m}$ (Lorius and others 1979). $\dot{\varepsilon}_{27}$ is about $10^{-13} \mathrm{~s}^{-1}$. From Ritz and others (1982), the ice temperature is $-53^{\circ} \mathrm{C}$ at the snow-ice transition and $-47^{\circ} \mathrm{C}$ at $900 \mathrm{~m}$. From the deformation map given by Goodman and others (1981), creep appears to be dominated by diffusional creep down to $905 \mathrm{~m}$. The normal grain growth structure illustrated in Figure 1 supports this assumption. 1.3 Formation mechanisms of single-maximum fabrics

Sing Te-maximum fabrics are frequently observed in Antarctic fce (Lorfus and Vallon 1967, Kizaki 1969, Anderton 1974, Gow and W1111amson 1976, Russel1-Head and Budd 1979). In the Byrd ice core, Gow and W1111amson (1976) found an increase in the preferred c-axis orientation from the surface down to $1200 \mathrm{~m}$. Fabrics with vertical c-axes are observed between 1200 and $1800 \mathrm{~m}$. A transformation from single- to multiplemaximum fabrics occurs below $1800 \mathrm{~m}$. This variation in the crystal orlentation fabrics with depth seems to be typical of cold ice sheets (Russell-Head and Budd 1979).

It is important to determine the mechanisms for the formation of these single-maximum fabrics. Hooke and Hudleston (1980) suggest that marked singlemaximum fabrics occur at large cumulative strains or high stresses. For the Byrd ice core, assuming that the horizontal velocity is uniform along the core and provided that the ice thickness is constant, the vertical strain-rate is given by Equation (3). With $b=173 \mathrm{~mm}$ of fce $a^{-1}$ and $H=2164 \mathrm{~m}$ (Gow, 1975), $\varepsilon^{*}$ is slightly less than $10^{-4} \mathrm{a}^{-1}$. At $1200 \mathrm{~m}$, the total compressive strain in the vertical direction could be nearly $100 \%$. This strain might be high enough to produce a strong fabric. However, the direction of the c-axes does not correspond to that induced by basal glide.

The vertical c-axes could be produced by horizontal shear. The shear stress $\tau$ caused by the surface slope $\alpha$ is

$$
\tau=\rho g h \sin \alpha
$$

where $\rho$ is the density, $g$ the acceleration due to gravity, and $h$ the depth. With $\alpha=0.0022$ rad, taken from the contour maps dated 1964 of the American Geographical Society, the shear stress increases with depth and is only $0.2 \times 10^{5} \mathrm{~Pa}$ at $1200 \mathrm{~m}$. The corresponding shear strain-rate, deduced from the deformation maps given by Goodman and others (1981) for isotropic ice, is only $3 \times 10^{-5} \mathrm{a}^{-1}$. The singlemaximum fabrics found in the Byrd ice core therefore cannot be induced by horizontal shear.

This is supported by the fabrics study made by Korotkevich and others (1978) on the Vostok ice core. A gradual increase in the preferred $c$-axis orientation of ice crystals is observed from the surface downwards. Fabrics with vertical c-axes are developed above $900 \mathrm{~m}$. Considering that the surface slope near Vostok is very small $(\alpha<0.0013 \mathrm{rad})$ and the low ice temperature $\left(<-55^{\circ} \mathrm{C}\right)$ down to $900 \mathrm{~m}$, the progressive near vertical orientation of the $c$-axes cannot be produced by the horizontal shear, as for the Byrd ice core.

A possible explanation for the formation of single-maximum fabrics in Antarctic ice is the selective growth of ice crystals with a vertical c-axis orientation. During the grain growth process, as observed in the Dome $C$ ice (Fig.1), the larger crystals grow at the expense of the smaller ones. The single-maximum fabrics could arise from the selective growth of crystals with a vertical c-axis orientation in the first metres of the firn induced by the important thermal gradient. Another possible explanation is the growth of favourably oriented crystals with regard to the state of stress, as explained by Kamb (1959). The favoured crystal orlentations are those which would have nearly maximum elastic strain energy if ice is only thinned in the vertical direction. Both these fabric formation mechanisms are compatfble with diffusional creep. Obviously, this fabric promotes horizontal shear and from one depth, the dislocation creep will be the dominant creep mechanism, stopping grafn growth and making stronger fabrics. A fabric study of the Dome $C$ ice core is in progress to test these assumptions.

\subsection{Ice viscosity in relation to fabrics}

An ice sample with the fabric shown in Figure 2 was tested at first in torsion and then in compression with the apparatus described by Duval (1976).

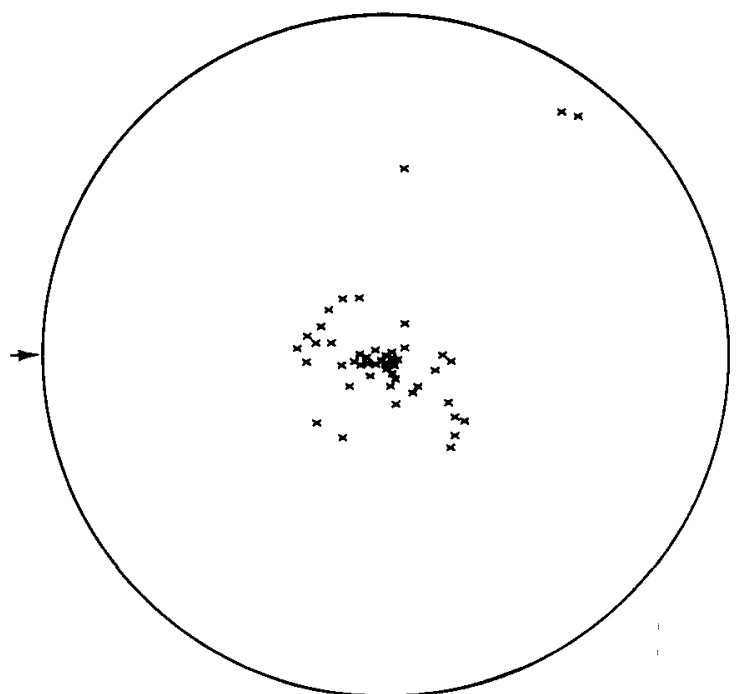

Fig.2. C-axis plot for the sample tested in torsion and compression.

The sample was cut so as to have the best orientation for basal glide in torsion (c-axis of crystals parallel to the axis of the cylinder) and, as a result, the least favourable orientation for basal glide in compression. The diameter of the sample was $90 \mathrm{~mm}$ and the length was $130 \mathrm{~mm}$. Crystal size was around $6 \mathrm{~mm}$. The effective shear stress was $1.35 \times 10^{5} \mathrm{~Pa}$ for the two stress cases and the temperature was $-7^{\circ} \mathrm{C} \pm 0.1^{\circ} \mathrm{C}$. Results are given in Table I. The effective shear strain-rates were calculated after $50 \mathrm{~h}$. A very large variation in parameter $B$ of Equation (1) was found. The strain-rate in torsion is $40 \times$ the strain-rate in compression and about $10 \times$ the minimum strain-rate calculated with isotropic ice. These results are in accordance with those of Lile (1978) for smaller shear stresses. However, this study gives a higher enhancement factor (strain-rate relative to that of the isotropic ice), probably induced by a more pronounced fabric.

Creep recovery tests were also performed to verify the influence of preferred orfentation on the 
TABLE I. EFFECTIVE SHEAR STRAIN-RATE $\dot{\gamma}$ AND VALUES OF THE CONSTANT B $\left(\dot{\gamma}=B \tau^{3}\right)$ FOR ANISOTROPIC ICE. $\tau=1.35 \times 10^{5} \mathrm{~Pa}, \mathrm{~T}=-7^{\circ} \mathrm{C} \pm 0.1^{\circ} \mathrm{C}$. THE VALUE OF B FOR ISOTROPIC ICE IS ALSO GIVEN (FROM LE GAC UNPUBL ISHED )

\begin{tabular}{lll} 
& $\begin{array}{c}\dot{y}\left(\mathrm{a}^{-1}\right) \\
\text { Effective shear } \\
\text { strain-rate }\end{array}$ & $\begin{array}{c}\mathrm{B} \\
(\text { bar }\end{array}$ \\
\hline Torsion & 0.610 & $0.25 \pm 0.02$ \\
Compression & 0.0125 & $0.005 \pm 0.0005$ \\
\hline & I sotropic ice & 0.02 \\
\hline
\end{tabular}

strain measured after unloading. Typical creep recovery curves are shown in Figure 3 in torsion and compression with the same sample discussed above. The loading time before unloading was always about $50 \mathrm{~h}$. As for creep tests, recovery strain strongly depends on the orientation of the basal planes with respect to the planes of maximum shearing stress. The strain measured after unloading in torsion is about $20 \times$ the expected elastic strain calculated with a shear modulus equal to $3 \times 10^{9} \mathrm{~Pa}$. These results bear out that recovery creep is produced by the glide of dislocations induced by internal stresses (Duval 1978).
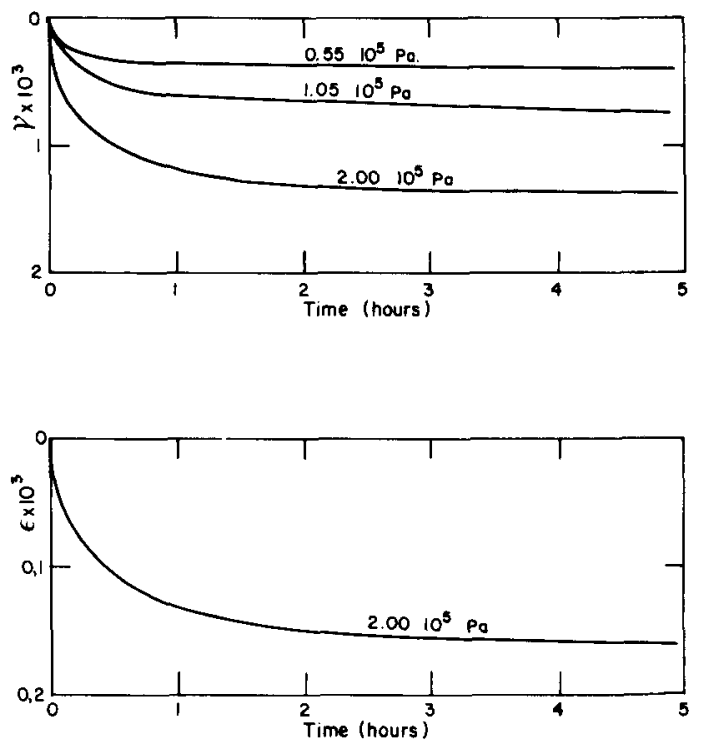

Fig.3. Creep recovery curves after unloading in torsion and compression. Temperature is $-7.2^{\circ} \mathrm{C}$. The fabric of the studied sample is given in Figure 2.

\section{CREEP ACTIVATION ENERGY}

Mechanical creep tests were performed with the apparatus described by Duval (1977) in a cold room with the temperature varying between $-30.2^{\circ} \mathrm{C}$ and $-4.9^{\circ} \mathrm{C}$. The maximum variation of the measured air temperature during a test was $0.2 \mathrm{deg}$.

Creep tests were performed in torsion on a sample from the Dome $C$ ice core (depth: $155 \mathrm{~m}$ ). Crystal size was about $6 \mathrm{~mm}^{2}$. It is important to note that at this depth the crystal size measured in the field was less than $2 \mathrm{~mm}^{2}$.

This result was discussed by Vassoille and others (1980). No significant preferred orientation of $c$-axes was found. A constant torque was applied for this test. The shear stress calculated for the outer surface of the cylinder was about $2.8 \times 10^{5} \mathrm{~Pa}$. The first creep test was conducted at $-7.2^{\circ} \mathrm{C}$. A minimum creep rate was measured for a strain of $1 \%$. No measurable variation of strain-rate was found over a time interval of about $24 \mathrm{~h}$. Next, the cold-room temperature was changed. Creep rate for the new temperature was measured $24 \mathrm{~h}$ after the temperature change. The same strain-rate values were also found during the decrease and the increase of temperature.

Results are given in Table II. Below $-7.2^{\circ} \mathrm{C}$, the calculated apparent activation energy $Q$ is

$78 \pm 1 \mathrm{~kJ} \mathrm{~mol}^{-1}$. Above this temperature, the increase in $Q$ always observed in polycrystals was noted. The activation energy derived by Barnes and others (1971) below $-8^{\circ} \mathrm{C}$ is similar to the value found in this study. It is higher than the value for self-diffusion found by Ramseier (1967). Taking into account the temperature dependence of the elastic modulus, Homer and Glen (1978) calculated the corrected activation energy for polycrystalline ice and suggested that, except at very high temperatures, the rate limiting mechanism is that which controls the glide of dislocations across the basal plane.

From Duval (1978) and Le Gac and Duval (1980), the strain-rate limiting mechanism appears to be recovery processes. Consequently, the steady state strain-rate can be written

$$
\dot{\varepsilon}=\frac{r}{h},
$$

where $r$ is the recovery rate and $h$ the strain-hardening coefficient (Duval 1976).

The activation energy for creep depends mainly on the variation of the recovery rate with temperature. However, the temperature dependence of the strainhardening coefficient cannot be neglected. From Le Gac (unpublished), the coefficient $h$ for a natural ice sample from $D 10$ station, Antarctica, is $1.5 \times 10^{9} \mathrm{~Pa}$ at $-10^{\circ} \mathrm{C}$ and $2.1 \times 10^{9} \mathrm{~Pa}$ at $-20^{\circ} \mathrm{C}$. Taking into account the variation of the strainhardening coefficient with temperature, the activation energy for the recovery rate would be about $60 \mathrm{~kJ} \mathrm{~mol}^{-1}$. This value is near the one given by Ramseier (1967) for self-diffusion.

Work is now in progress to determine the recovery processes which should control strain-rate in polycrystalline ice when dislocation creep is the dominant mechanism.

TABLE II. VARIATION WITH TEMPERATURE OF $\dot{\gamma}$ AND B

$$
\tau=2.8 \times 10^{5} \mathrm{~Pa}
$$

\begin{tabular}{lcccccccc}
\hline$T\left({ }^{\circ} \mathrm{C}\right)$ & -4.9 & -6.8 & -7.2 & -12.1 & -15.8 & -20.1 & -25.1 & -30.2 \\
\hline$\dot{\gamma}\left(\mathrm{a}^{-1}\right)$ & 1.05 & 0.74 & 0.65 & 0.33 & 0.20 & 0.11 & 0.053 & 0.022 \\
\hline B & 0.048 & 0.034 & 0.03 & 0.015 & 0.009 & 0.005 & 0.0024 & 0.001 \\
\hline
\end{tabular}


ACKNOWLEDGEMENTS

We thank A Chaillou for extensive technical assistance and the Centre National de 1a Recherche Scientifique for financial support. This work is a contribution to the International Antarctic Glaciological Project.

\section{REFERENCES}

Anderton P W 1974 Ice fabrics and petrography, Meserve Glacier, Antarctica. Journal of Glaciology 13(68): 285-306

Barnes P, Tabor D, Walker J C F 1971 The friction and creep of polycrystalline ice. Proceedings of the Royal Society of London Ser A 324(1557): 127155

Duval P 1976 Lois du fluage transitoire ou permanent de la glace polycristalline pour divers etats de contrainte. Annales de Géophysique 32(4): 335350

Duval P 1978 Anelastic behaviour of polycrystalline ice. Journat of Glaciology 21(85): 621-628

Duval P, Lorius C 1980 Crystal size and climatic record down to the last ice age from Antarctic ice. Earth and Planetary Science Letters 48(1): 59-64

Goodman D J, Frost H J, Ashby M F 1981 The plasticity of polycrystalline ice. Philosophical Magazine A 43(3): 665-695

Gow A J 1975 Time-temperature dependence of sintering in perennial isothermal snowpacks. International Association of Hydrological Sciences 114 (Symposium of Grindelwald 1974 - Snow Mechanics): 125-141

Gow A J, Williamson T 1976 Rheological implications of the internal structure and crystal fabrics of the West Antarctic ice sheet as revealed by deep core drilling at Byrd station. CRREL Report 76-35

Homer D R and Glen J $W 1978$ The creep activation energies of ice. Joumal of Glaciology 21(85): 429-444

Hooke R L, Hudleston P J 1980 Ice fabrics in a vertical flow plane, Barnes Ice Cap, Canada. Joumal of Glaciology 25(92): 195-214

Kamb W B 1959 Theory of preferred crystal orientation developed by crystallization under stress. Joumal of Geology 67(2): 153-170

Kizaki K 1969 Ice fabric study of the Mawson region, East Antarctica. Joumal of Glaciology 8(53): 253-276

Korotkevich Ye S, Petrov V N, Barkov N I, Sukhonosova L I, Dmitriyev D N, Portnov V G 1978 Rezul'taty izucheniya vertikal'noy struktury lednikovogo pokrova Antarktidy $v$ rayone stants $i$ Vostok [Results of the study of the vertica] structure of Antarctic ice sheet in the vicinity of Vostok station]. Informatsionnyy Byulzeten' Sovetskoy Antarkticheskoy Ekspeditsii 97: 135-148

Le Gac H, Duval P 1980 Constitutive relations for the non elastic deformation of polycrystalline ice. In Tryde P (ed) International Union of Theoretical and Applied Mechanics. Physics and mechanics of ice. Symposium Copenhagen, 1979. Berlin, Springer-Verlag: 51-59

Le Gac H Unpublished. Contribution a la determination des lois de comportement de la glace polycristalline. (Thèse de 3 e cycle, Université de Grenoble, 1980)

Lile R C 1978 The effect of anisotropy on the creep of polycrystalline ice. Joumaz of GLaciology 21(85): 475-483

$L$ liboutry $L$ In press. Analytical models for the flow of cold ice sheets. Journal of Glaciology Lorius C, Vallon M 1967 Etude structurographique d'un glacier antarctique. Comptes Rendus des Séances de l'Académie des Sciences Ser D 265(4): 315-318
Lorius C, Merlivat L, Jouzel J, Pourchet M 1979 A 30,000-yr isotope climatic record from Antarctic ice. Nature 280(5724): 644-648

Ramseier $R 01967$ Self-diffusion of tritium in natural and synthetic ice monocrystals. Joumal of Applied Physies 38(6): 2553-2556

Ritz C, Lliboutry L, Rado C 1982 Analysis of a $870 \mathrm{~m}$ deep temperature profile at Dome C. Annazs of Glaciology 3: 284-289

Russe11-Head D S, Budd W F 1979 Ice-sheet flow properties derived from bore-hole shear measurements combined with ice-core studies. Journal of Glaciology 24(90): 117-130

Vassoille R, Ma i C, Perez J, Tatibouet J, Duval P, Maccagnan M 1980 Anomalous behaviour of Dome $C$ ice core (East Antarctica) studied by mechanical damping measurements. Annales de Géophysique 36(4): $49 \uparrow-498$ 